\title{
Conceptualizing and Communicating SoTL: A Framework for the Field
}

\begin{abstract}
The emerging field of SoTL is an inherently interdisciplinary endeavor which requires embracing a diverse range of research methods and disciplinary differences in world views. This diversity has caused a lack of coherence in its conceptualization and communication, which can be confusing for new scholars. Ongoing debates in the community concern the use of theory and methodology, as well as definitional questions of what constitutes SoTL and the nature of its purpose. This article offers a framework for conceptualizing the field which attempts to broadly delineate the available learning theories underlying and methodologies appropriate to studying teaching and learning, while intending to be hospitable to a broad range of diverse disciplines. Further, the framework illustrates the tacit links between learning theories and methodologies, serving as a guide to potential approaches to SoTL work. The framework is illustrated with example SoTL studies. It is hoped that the framework will help ground future SoTL investigations in appropriate theories and methodologies, and build interdisciplinary communication and understanding in the "trading zone" that is SoTL.
\end{abstract}

\section{KEYWORDS}

SoTL, field, methodology, learning theory, framework

\section{INTRODUCTION}

As an emerging and developing interdisciplinary field, the Scholarship of Teaching and Learning (SoTL) is rich with debate about its nature and purpose (Poole, 2013a). In order to define the field and communicate guidelines for good practice, many leaders in the field have developed criteria or taxonomies for defining and evaluating SoTL. Most criteria are written very generally, such as "clear goals, adequate preparation, appropriate methods" (Glassick, Huber, \& Maeroff, 1997, p. 36) or "methodologically sound" (Felten, 2013, p. 122). Others have developed taxonomies based on levels of analysis. For example, Nelson (2003) divides the field into reports on particular classes, reflections on many years of teaching experience, comparisons of courses or students across time, learning science, and summaries and analyses of sets of prior studies, while Hutchings (2000) delineates the oft referred to "what is," "what works," "visions of the possible," and "formulation of new conceptual frameworks" (pp. 4-5). 
The authors of this paper came to SoTL from two very different backgrounds, to an institutional program designed to support and develop beginning SoTL researchers. At the time, we found that, while simple enough to be inclusive of various disciplinary perspectives and methods, the above descriptions did not help new scholars understand the variety of perspectives and methods of SoTL, nor how "soundness" or "rigor" of method is evaluated. Janice was an engineering professor and found that developing a SoTL research question without being able to articulate any philosophical or theoretical underpinnings made her feel unsettled and unscholarly. Michelle, coming from an interpretive educational research background, found puzzling resistance to utilizing what she saw as highly relevant research methodologies and theory from the field of education in SoTL. Hence, we both embarked on our overlapping journeys to better understand the field. In our ensuing reading and discussions within the SoTL community, and in our subsequent work with new scholars at our university, we discovered a pervasive belief that educational research is restricted to empirical, if not quantitative, generalizable studies such as those found in educational psychology. While this is one kind of study certainly, there is a long history in education of classroom-based research done by teachers that utilizes a wide variety of approaches potentially of value to SoTL. There is also much theoretical, philosophical, and critical work. Additionally, we found that the lack of explicitly articulated theory in some SoTL work can lead to an impression that the field is somewhat a-theoretical, and while this may make it quickly accessible to practitioners steeped in their own disciplines, those who are less familiar with theories and methodologies appropriate for researching teaching and learning are sometimes at a loss as to how to proceed when designing a research project. We argue that underlying any inquiry about teaching and learning are particular stances and world views about such things as how learning works, as well as assumptions about methodology. Neglecting to articulate these in the effort to make SoTL more accessible can contribute to a perception that a lack of rigor is acceptable in SoTL.

Learning science tells us that organization of knowledge into frameworks is key to learning a discipline (Ambrose, Bridges, DiPietro, Lovett, \& Norman, 2010; Leamson, 1999; Zull, 2002). Therefore, in this paper, we add to the existing general definitions of SoTL by addressing some of the theoretical, methodological, and definitional questions being debated in the field and offering a conceptual framework for SoTL which is inclusive of many disciplines and research traditions. In order to describe and illustrate the framework, we first broadly outline existing categories of learning theories and research methodologies commonly used to investigate teaching and learning in the field of education, and then use the framework and a variety of published SoTL studies to describe the intersections of different research approaches and perspectives on learning. We have found this framework to be helpful in working with SoTL practitioners at our institution as they develop their work, both new practitioners as well as more experienced researchers participating in an ongoing SoTL Community of Practice. By sharing it, we hope to help build interdisciplinary communication and understanding in the "trading zone" that is SoTL.

\section{What is SoTL? Theoretical, methodological, and definitional debates}

SoTL has typically been defined by the kinds of questions it asks, for example by being "focused on student learning" (Felten, 2013, p.122). While such general definitions are intended to be inclusive of different disciplines and different epistemologies, 
ongoing debates in the multidisciplinary SoTL community concern the use of theory and methodology as well as definitional questions of what constitutes SoTL and the nature of its purpose.

Theory and methodology are inextricably linked to each other as well as to the research question, whether implicitly or explicitly. As will be explained in more detail in the following sections, theory can be used to articulate assumptions about how people learn, and methodology articulates assumptions about the nature of knowledge and helps explain why a study was conducted in a particular way. However, few articles about the nature of SoTL discuss theory and methodology together. For example, Chick (2014) embraces diverse methodologies and method but does not discuss theory, while Dikson and Treml (2013) acknowledge the importance of theory but have a narrower perspective on the nature of SoTL (measuring the impact of a teaching intervention, i.e. an experimental methodology). In fact, in a 9-chapter special issue on "Measuring Systematic Changes to Teaching and Improvements in Learning” (Gurung \& Wilson, 2013) containing 3 chapters on experimental research design and one on statistics, there is only a brief, one-paragraph acknowledgement that "qualitative studies are complementary and just as useful" (p. 31). If a new practitioner were to come upon this resource early in their exposure to SoTL, they might have a very narrow understanding of the field and might never "enjoy the benefits of studying learning and teaching from diverse research and theoretical perspectives" (Poole, 2013b, p. 140).

While the field has begun to embrace increasingly diverse research methods (e.g., Hubball \& Clarke, 2010), the question of "what is SoTL" remains alive. In contrast to the predominantly experimental view of SoTL, others argue that questions about what works and generalizability are simply not answerable empirically in SoTL (Barrow, 2006; Grauerholz \& Main, 2013). Recently, Grauerholz and Main (2013) worry that the SoTL movement will be "shaped by (hegemonic) standards that privilege certain types of methodologies over others" (p.152), and yet McKinney (2013), in describing the increasing interdisciplinarity of SoTL, wonders "at what point - if any - does such work become something other than SoTL?” (p. 3). We argue, as does Poole (2013b), that by embracing a broader definition of research for the field, we can get past our disciplinary debates and focus on understanding student learning. We propose that SoTL should be defined by the goals of deepening our understanding of student learning and, as Kreber (2013) advocates, exploring not only the "effectiveness but also the desirability of what we do in and through higher education” (p. 858). In expanding or even debating the goals of SoTL, the field will need to recognize a broader range of qualitative approaches which could provide additional perspectives and entry points but also render it increasingly important that those approaches are explained and justified for a wide SoTL audience.

Entwined with debates about theory and methodology lies the question of how SoTL is different from the field of educational research. In describing itself as different, SoTL discourse typically refers to education as being empirical, social science research. For example, Bernstein (2010) compares SoTL to "traditional educational research" by contrasting "rich description" with "generalizability." Similarly, in arguing for the "fallacy of control groups in classroom research," it is apparent that Grauerholz and Main (2013) consider educational research to be experimental in nature. As a result, they incorrectly reference Kanuka (2011) when they decry that "many SoTL researchers continue to define SoTL as an extension of educational research, with methodologies consistent with 
those in traditional disciplines" (p. 156). In fact, Kanuka's article is more focused on the need for theoretical frameworks and building on existing literature in SoTL and less on methodology. However, in a brief discussion of typical methodologies in the field of education, she does mention not only scientific and positivistic methodologies, but also naturalistic and interpretive methodologies as well as critical theory (please see below for descriptions) which enrich and move beyond social science. In other words, Kanuka does not argue that SoTL should be experimental or empirical in design at all.

SoTL has also been described as different from the field of education because it is a "methodological and theoretical mutt" (Felten, 2013, p. 121) that reaches across disciplines, methods, and perspectives rather than being siloed in one particular discipline or methodology. We argue the same could be said of the field of educational research. While it is true that there are siloed areas of work in educational research ranging from that of quantitative researchers to critical theorists, other researchers in the field also use mixed methods and multiple theoretical frameworks. Yet in educational research using mixed methods, there is still an understanding that different methodologies align with certain theoretical perspectives and methods of collecting data and are determined by the kinds of research questions one wishes to ask about learning. In other words, methodological choices are not entirely separate from choices of theoretical perspective and world view, so while the field as a whole may be a mutt, any individual SoTL study still needs to be consistent in its methodology, method, and perspective. In other words, we feel that by defining itself as a field independent of education, SoTL has created an unnecessary tension. The reality is that many similar kinds of questions are being investigated in both fields. Education itself borrows heavily from a variety of other disciplines, and it seems non-productive to ignore the potentially fruitful overlap with SoTL.

In summary, we suggest that, for a number of reasons, members of the multidisciplinary field of SoTL could benefit from a better understanding of the range of lenses and methodologies used in educational research. SoTL researchers can benefit from being aware of their philosophical approach and theoretical assumptions about learning because it will help them ask new questions, design better studies, and also more strongly articulate their findings, especially to colleagues with different world views. This will also benefit the field, not only by improving communication and understanding across disciplines, but also because theoretically grounded work is one way for SoTL to achieve broader impact across studies and make new contributions to knowledge about teaching and learning beyond single classrooms.

\section{THEORETICAL AND METHODOLOGICAL PERSPECTIVES FROM THE FIELD OF EDUCATION}

All research involves three elements: 1) a research question/philosophical stance/ epistemology (either explicitly or implicitly); 2) theoretical grounding or foundation (stated or implied); and 3) methodological rigour. In what follows, we focus on 2) and 3) by briefly outlining the major categories of learning theories and methodologies and the importance of congruence between them, and by providing examples of SoTL studies in this framework. We have deliberately oversimplified to provide an introduction to those who may be new to learning theory and methodology; we also offer references for more information. 


\section{Learning theories}

A learning theory provides a framework upon which researchers are basing their assumptions about the nature of learning, either explicitly or tacitly. While we recognize that SoTL scholars may draw upon theories from other disciplines as well, in studying learning, they also have an implicit or explicit way of thinking about learning. One helpful way to broadly categorize learning theory is into behaviorist, cognitivist, constructivist, and humanist categories. It is useful, when reading a SoTL study, to understand the basic assumptions of the researcher in terms of how learning works and how this framework can be employed to think about these assumptions.

\section{Behaviourism}

This perspective on learning developed in the early $20^{\text {th }}$ century and suggests that all behavior is based upon external stimuli-or the idea that environmental changes lead to behavioral change as evidence of learning (Gurung \& Schwartz, 2013, p. 35). Behaviour is seen as being shaped by positive and negative reinforcement. "Pavlov's dog" is a wellknown example demonstrating classical conditioning leading to a physiological response (p. 35). B.F.Skinner further developed the theory of operant conditioning, which is more applicable in classroom settings as it focuses on the shaping of behaviour (rather than physiological responses) through reinforcement, "if the reinforcer is contingent upon the learner's behaviour” (Naested, Potvin, \& Waldron, 2004, p. 74). While behaviourism is currently less 'fashionable' in educational research circles, we see many powerful vestiges of the approach in our schooling systems, such as the reward of grades for student work. Many studies, in fact particularly those that take approaches borrowed from the field of Psychology, often take a more behavioural approach. In these studies, learning is defined in behavioural terms, for example, how students might be motivated to study more frequently.

\section{Cognitivism}

This theory considers learning as a mental process involving the creation of schema, structures, and models. The mind is seen as a "black box" or information processor with "a focus on a person's own mental activities rather than on the environment" (Gurung \& Swartz, 2013, p. 35). It replaced behaviourism as the dominant paradigm in the 1960s. Cognitivist theories prioritize memory, thinking, and problem-solving, and "directed psychologists to examine the determinants of learning and memory, with an emphasis on understanding the acquisition of knowledge in humans" (Gurung \& Schwartz, 2013, p. 36). Learning is defined as a change in a learner's schemata. Benjamin Bloom's (1956) well-known and still utilized taxonomy of educational goals (knowledge, comprehension, application, analysis, synthesis, and evaluation), or the current work in Decoding the Disciplines (Middendorf \& Pace, 2004) are examples of cognitivist perspectives in practice.

\section{Constructivism}

Constructivism builds on cognitivism, viewing learning as an active, "constructive" process. New information is linked to prior knowledge, and subjective representations of reality are created. Past experience and cultural factors influence learning. Important early work in constructivism was done by Vygotsky, Piaget, and Dewey, often considered the father of experiential learning (Naested et al., 2004, p. 85). Social constructivism, which 
recognizes the impact of interaction with others on learning, is a further development. Notions such as 'active learning' and "communities of practice" (Lave \& Wenger, 1991) are rooted in constructivist and socially constructivist principles.

\section{Humanism}

Humanism, a paradigm that also emerged in the 1960s, is based upon ideas of freedom, dignity, and the potential of human beings. Maslow's hierarchy is the well-known model (Maslow, 1970, cited by Naested et al., 2004, p. 94). The world view here is that people act with intentionality according to their core values. Focusing on the whole learner, rather than only the thinking aspect of the person, is key. Humanist approaches are common in the caring professions such as nursing and social work.

\section{Methodology}

The second element that needs articulation is the methodology of the study. This should be seen as distinct from method, which is simply a description of how the participants were selected, and the data collected and analyzed. Methodology explains why it was done this way, and again articulates the assumptions and epistemology (world view) of the researchers (Burton, 2002, p. 4). While many SoTL studies may collect work samples or interview students, what is done with this data and what is looked for depends largely upon the methodology. For example, if a more empirical approach is taken, measurement of change will be sought, whereas in a critical study, the researcher is attuned to questions of privilege and power. In most qualitative approaches, generalizability is typically not an aim of the research but rather a rich, contextual ("thick") description to ensure trustworthiness. The onus is then on the reader to determine whether the findings are transferable to other contexts. Broad categories of methodological approaches are briefly described below.

\section{Quantitative}

Quantitative studies typically take a positivist perspective, which assumes that there is a single truth or knowable world which is independent of context, observer, or the observed (Chism, Douglas, \& Hilson, 2010). This type of research is hypothesis-driven, and its purpose is to find relationships among variables and/or to define cause-and-effect. The methods and variables are defined in advance, and the research design must address validity, reliability, and generalizability (Gurung \& Wilson, 2013). A more recent development can be considered post-positivist, whereby the influence of the researcher's assumptions is recognized, and in which "one can only say that current data is consistent with an assumed truth" (Chism et al., 2010, p. 2). Objectivity is still sought. Behaviourist, cognitivist, and sometimes constructivist questions about teaching and learning could reasonably be posed, but humanist research questions are less likely to be answerable using a quantitative methodology.

\section{Qualitative empirical}

Some research uses qualitative data sources and does not have an experimental design, but is still empirical in its approach; its underlying goal is to discover aspects of an observable reality, and it attempts to be as objective as possible in its approach. In a SoTL study, the emphasis in data collection is on observing learning as demonstrated (such as through a think-aloud interview) rather than inferring that learning has occurred (for 
example, by asking students to self-report or reflect upon their learning). Empirical questions, because they imply observation, tend to be most aligned with behaviourist and cognitivist learning theories. Behaviour is directly observable, whereas cognitive processes can be observed through tasks clearly defined by the researcher.

\section{Naturalistic}

Naturalistic studies reject the notion that controlling for variables is desirable or even possible in research, but rather pose that each research situation is unique and that data should be gathered from their situated context (Lincoln \& Guba, 1985). Thus, these types of studies do not align with more behaviourist or cognitive perspectives on learning. Naturalistic research approaches such as ethnographies are anchored in anthropology and used to study a given culture with an emphasis on fieldwork and participant observation. These approaches can be fruitfully applied to teaching and learning contexts as sociocultural contexts, for example, observations of group processes, and analysis of artifacts such as coursework. Thus, this methodology is most appropriate for social constructivist perspectives on learning.

\section{Interpretive}

Interpretive approaches derive knowledge claims from the interpretation of experiences, and thus do not try to prove generalizability at all. Instead, they assume that social reality is locally and specifically constructed (Lincoln \& Guba, 1985) and that the knowledge produced is idiographic in nature. In other words, multiple subjective realities are possible. In interpretive methodologies, methods and approaches emerge and are adjusted during the study. Rather than judging interpretive research on generalizability, quality in interpretive research must be judged through trustworthiness. Using Hutchings' (2000) taxonomy, interpretive approaches would be considered a "what is" type of approach. Theories of learning that align with this methodology tend to be constructivist and social constructivist perspectives. Hermeneutic, narrative inquiry, phenomenographic, and phenomenological approaches are examples of interpretive methodologies. These approaches are most easily employed for constructivist, social constructivist, and humanist questions.

\section{Critical theory}

The critical perspective examines power relationships present in society and, therefore, recognizes truth in multiple subjective realities, since truth defined by those in power is different than by those who are marginalized. Kreber (2013) suggests that discourse in SoTL has been so oriented to "what works" that it tacitly ignores questions of social justice and ethics. She argues that such questions are inseparable from "what we think we are committed to in the scholarship of teaching and what we consider its purpose to be" ( $\mathrm{p} .858)$. This perspective then leads us towards a critical approach which is designed to illuminate inequities and could ask questions about race, class, and gender and how they play out in a pedagogical space, in other words mainly humanist and potentially socially constructivist kinds of questions.

\section{Postmodern}

Postmodern analyses include diverse and contradictory critiques that "resist, subvert, and refuse any structural formation” (Denzin \& Lincoln, 2013, p. 455). Its discourses 
are deconstructive in that they seek to make us skeptical about beliefs concerning truth, knowledge, power, the self, and language that are often taken for granted. The purpose is to deconstruct existing 'grand narratives' or theoretical frameworks that describe social behavior, and the outcome is a reconceptualized description of a phenomenon. This research methodology might indeed reject the notion of a unifying learning theory and challenge the researcher to consider a multiplicity of perspectives, including an individual's potential resistance to learning (Ellsworth, 1997).

\section{ACONCEPTUAL FRAMEWORK FOR SOTL}

To provide an inclusive conceptual framework for SoTL research and to demonstrate how methodological and theoretical perspectives can be aligned, we used the two spectrums described above to create a two-dimensional framework. To illustrate theframework, we began by mapping to it a selection of recent publications from SoTL scholars in various disciplines at Mount Royal University (Figure 1), chosen because the authors gave us permission and because their studies demonstrate variety in methodology and perspectives on learning. To fully illustrate the framework, we also chose two more published studies to fill in the gaps. All studies are briefly summarized below, with references provided, and are described in order starting from the top left of the framework, moving down and to the right. Readers are encouraged to examine each publication in more detail if they desire to gain a full appreciation of the nature of these studies and their approaches and outcomes.

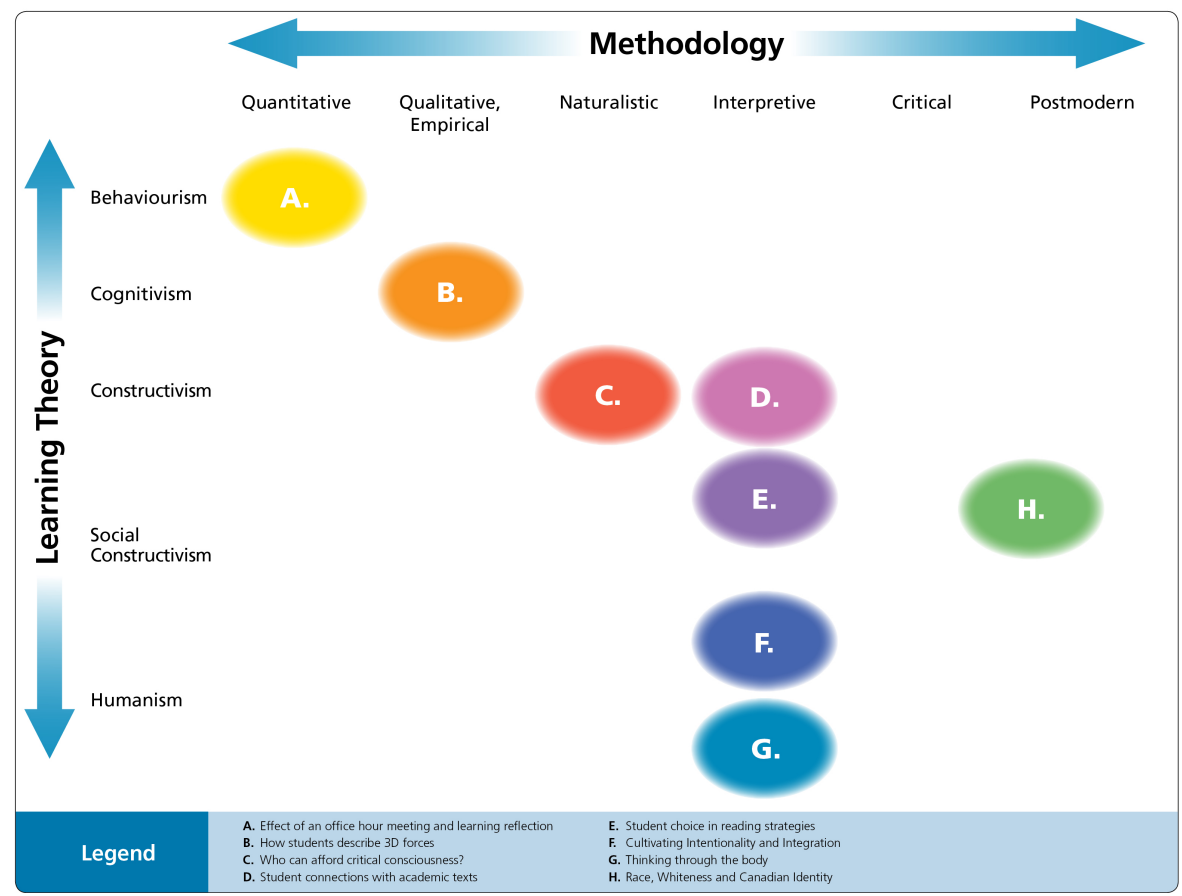

Figure 1. A methodological and theoretical framework to conceptualize and communicate SoTL, illustrated with examplestudies. 
A. McGrath, A. (2014). Just checking in: The effect of an office hour meeting and learning reflection in an introductory statistics course. Teaching of Psychology, 41(1), 83-87.

McGrath's (2014) study of students' learning in a psychology statistics course took a quantitative, experimental approach. Recognizing the value of professor-student rapport as well as asking students to reflect on their learning, McGrath devised an intervention which she called a learning check-in where students were required to have an individual meeting with her, followed by completing a reflection form which asked them to assess their own learning and behaviours and to develop a plan to succeed in the course. Students were randomly assigned into two groups that had the learning check-in at different times in the semester. The effect of the intervention was measured by performance on several tests, which also allowed for checking the equivalency of the two randomly assigned groups.

We place this study primarily in the behavioural category since the intervention was largely targeted to improving students' study habits. The researcher hypothesized that, based on previous research, the opportunity to build professor-student rapport would improve learning outcomes - in this way rapport becomes a motivator for changes in behaviour. In the reflection, students were asked "to (1) assess their learning to date; (2) consider behaviours that help and interfere with their learning; (3) identify three behaviours to adopt, change, continue, or stop to succeed in the course; and (4) develop a study plan for the upcoming test" (p. 84). The study had controls built in, including measures to control for instructor bias and "expectancy effects."

This kind of approach is common in Psychology and is a good example of a quantitative methodology where statistics are used to demonstrate results. Cognitivist assumptions are also intrinsic to the study, since demonstration of the effectiveness of the learning intervention was measured by test performance.

B. Miller-Young, J.E. (2013). Calculations and expectations: How engineering students describe three-dimensional forces. The Canadian Journal for the Scholarship of Teaching and Learning, 4(1).

Taking an empirical and qualitative approach to methodology and cognitivist learning perspective, Miller-Young (2013) was interested in the difficulties first-year engineering students experienced when learning to visualize the three-dimensional structures in their textbooks. Interested in capturing the students' thinking processes early in the semester, Miller-Young asked students to participate in a think-aloud interview, a protocol from cognitive psychology in which participants are asked to talk out loud about what they are thinking while working on a task (Streveler, Litzinger, Miller, \& Steif, 2008). By thematizing the think-aloud transcripts, Miller-Young was able to identify three major difficulties students experienced when learning to visualize the drawings in their text, and also found evidence of these difficulties in the students' coursework. The intent of the study was not to test a teaching intervention, but simply to identify typical challenges students encounter when learning the skill so that instructors can be more responsive to these difficulties.

With this cognitivist approach, the researcher was primarily interested in gaining better access to and understanding of learning processes as they occur-how students "think through" a complicated problem. The study is empirical because the data collected were observations of students, while the data collected was qualitative in nature and analyzed through a coding rather than statistical process. 
C. Seitz, D. (2004). Who can afford critical consciousness?: Practicing a pedagogy of humility. Creskill, NJ: Hampton Press.

As a socially conscious middle-class writing teacher, Seitz (2004) wondered how much he might have misread some students' motives and social meanings in their critical writing work because of his own upbringing and educational training. After analyzing his own students' work in terms of instrumentalism, difference, and resistance and questioning his own persuasive authority, he subsequently conducted ethnographic research with working class, minority, and immigrant students in a colleague's class about women in the third world. Seitz used classroom (field) observation and student interviews, and he also met regularly with his colleague to discuss her views of particular students and classroom dynamics. The book chronicles not only the findings of the research but also Seitz's pedagogical responses to and reflections on the issues raised.

Because students were asked to write individually in the courses, and the main focus of study was how students did or did not integrate ideas and values from the course into their lives, we place this study in the constructivist realm. The methodology is primarily naturalistic since Seitz describes himself as "an anthropologist studying culture that develops in the class" (p. 45), although as one might surmise from the topic and title of the study, there are critical perspectives as well. Seitz explicitly describes his research as ethnographic and discusses the importance of "membership role" (p. 45) and being a participant-observer, which are important aspects of research in anthropology. He also argues that the ethnographic methodology's emphasis on inductive theorizing helps him as a teacher to remain attentive to the complex and varying situations in his classroom and students.

D. MacMillan, M. (2014). Student connections with academic texts: A phenomenographic study of reading. Teaching in Higher Education, 19(8), 943-954.

As librarian teaching a research methods class for Public Relations, MacMillan (2014) was interested in ways to help students read scholarly materials at a deeper level by encouraging them to make connections with prior knowledge. She designed an assignment in which students were required to make and record such connections as part of an in-class reading activity, and she used a phenomenographic approach to analyze the variation in what sparked connections and what kinds of connections students made, in terms of both content and depth. The outcome of this study was a deeper understanding of students' reading processes and suggestions for ways of improving students' ability to engage more deeply with academic texts.

Phenomenography is an interpretive approach, but one that does not start with any preset categories in mind. As MacMillan (2014) states in her literature review, phenomenography "recognises that the categories of experience that emerge from the data are situated within that particular group, circumstance and time, and may not be generalisable to wider populations." MacMillan also explicitly states that phenomenography's emphasis on variation was congruent with the goals of the study, and its focus on relationships was congruent with her constructivist understanding of learning. These connections result in a coherence to her study.

E. Manarin, K. (2012) Reading value: Student choice in reading strategies. Pedagogy, 12(2), 281-297. 
In a study of students' choice in reading strategies, Manarin (2012) also took an interpretive approach, but with a more constructivist perspective, to examining students' reflective reading logs. In a course on critical writing and reading where she provided direction, prompts, and feedback, Manarin had students write ten reflective log entries where they described how they read different essays and reflected on the choices they made. Using her own disciplinary method of close reading and an open coding and recoding process, she identified five categories of actions students took in reading, and used patterns based on the purpose of the reading and whether the content was something students could personally connect with. She reports that she purposefully did not try to track patterns of change in strategies by the students as an objective observer, which would have been a more empirical approach, but deliberately intervened when she found students' strategies to be lacking and selected readings that would "force students away from some of their habitual choices" (p. 287).

We placed this study in the constructivist/social constructivist space because of the recognition that learning, learning about reading in this case, is done contextually and in conversation with others (in this case, mainly through feedback from the instructor on the reading logs). The importance of the students' prior learning experiences is acknowledged. A dialogical process in the reading logs is described. The researcher also writes consciously from her own vantage point, recognizing the importance of her perspectives, assumptions, and in a sense, participation in the study - her assumptions are explored but not controlled out, and she intervened when she felt it was pedagogically necessary. This, then, is an interpretive approach.

F. Carey, M. (2012). In the valley of the giants: Cultivating intentionality and integration. International Journal for the Scholarship of Teaching and Learning, 6(1).

In a first-year General Education Communities and Societies course, Carey (2012) investigated whether student intentionality and integrative learning could be cultivated by reflective journal writing and instructor prompts. Over the course of the term, students responded to questions such as "What do you bring to this learning experience?"; "What grade do you expect to get from this course - why?"; and "Are you a deep or a surface learner - why?" (p. 5). A constant comparison coding approach was used, looking in the journal reflections for themes of self-awareness, what works, and affect as indicators of intentionality as well as commentary on connections to school and life as evidence of integration. From her findings, Carey concludes that prompts did cultivate intentionality in students and also suggests that students are well aware of their movement between deep and surface approaches to learning to achieve different goals in different courses across their academic careers.

While the prompt "What do you bring to this learning experience?" also has constructivist elements, the focus in this study was on the values of the learners and how that influenced their approach to learning. The researcher was interested in self-awareness, and the goals and needs of the learner. She articulated insights about her own growth as a teacher through the experience of conducting the study. Because of the focus on intentionality and the whole learner and the context-dependent telling of individual stories or "many truths," we place this study in the humanist and interpretive realm.

G. Helberg, N., Heyes, C., \& Rohel, J. (2009). Thinking through the body: Yoga, philosophy, and physical education. Teaching Philosophy, 32(3), 263-284. 
This article describes an experimental course cross-listed between Philosophy and Education, entitled "Thinking through the body: Philosophy and Yoga," and the experiences of its professor and students. The course was designed to address a perceived gap between teaching theory and practice in teaching philosophy of the body, which was the oft-neglected idea that movement could be philosophical and that philosophy could be learned through movement. The course consisted of lectures, discussions of various readings, and also a weekly yoga practice. Students were encouraged to approach the texts, as well as their experience, as embodied subjects. The writing of the paper was a collaborative undertaking resulting from a small group discussion of both the professor's and students' experiences of the course. Through description and reflection on these experiences, the article demonstrates how what was learned by reading texts transferred to embodied knowledge, and vice versa. The article discusses both the professor's and the students' unease with evaluating the yoga practice since students were being asked to "refrain from judging themselves while nevertheless being judged” (p. 271). Another tension inherent in the course was that students were asked to reflect and write about their practice experience while immersion in meditative practice demands that the mind be still and detached.

This paper was chosen as another exemplar of a humanistic perspective because of its whole learner orientation, focusing not only on intellectual development, but also on spiritual and physical knowledge. The course itself introduced students to a phenomenological study, Leder's (1990) The Absent Body. This text is used as an important foundational literature both for the course and the study. Phenomenology is oriented towards embodiment and creating meaning from sensory experiences and the breaking down of the Cartesian dualism between mind and body. Phenomenology is also a research methodology concerned with describing the "essence" of phenomena and is located within an interpretive frame.

H. Easton, L. \& Hewson, K. (2010). Reflections on the interplay of race, whiteness and Canadian identity in a film studies classroom. Reception: Texts, Readers, Audiences, History, 2, 116-148.

In a film studies class with a focus on race and representation in Hollywood films, Easton and Hewson set out to encourage, engage with, and better understand students' readings of several films. Students' readings were made evident through journals, group discussion, on-line discussions, and focus groups. After discovering that the students were, indeed, attuned to critical discourses of race but had negotiated these into a form of liberal tolerance with underlying values of individualism, the authors argue that, in order for cultural studies' approaches to have power in the classroom, more attention must be given to the way students' pre-existing experiences of race can readily produce performances of critical readings of film texts (p. 119). They discovered that students were able to take a critical perspective when discussing black-white stereotypes and racism after watching Spike Lee's Bamboozled (2000), but remained critical and were unable to move to a reparative reading of Marc Forster's Monster's Ball (2001). They also noticed a double spectatorship in that their Canadian students were able to perform a critical reading of race and representation when talking about "other people's" (American) racism, but were unwilling to connect to personal investments or to recognize the problems of race in their own country. Thus, they criticize the "model of outcomes-based education where students learn to become adept at performing outcomes at a cogni- 
tive level without necessarily integrating those outcomes within affective frameworks" ( $\mathrm{p}$ 143). Finally, they came to realize that their goals for student reparative reading were more about their own wish for white repair.

This kind of study is unusual in the SoTL realm, and yet important as Kreber (2013) asserts to get beneath "what works" and to ask questions about why, why not, and who decides. Questions of power and privilege in the classroom largely go unasked, so far, in the SoTL landscape. This study is an example of a radicalized critical stance which means that it asks deconstructive questions about power, in this case in relation to race. The researchers consciously pursue a "transformative critical pedagogy" (p. 118), while their analysis deconstructs and asks unsettling questions of themselves and the reader.

These eight very different SoTL studies demonstrate a range of research approaches and (often implicit) perspectives on learning, and they are used to illustrate a conceptual framework for the field. The studies provide examples of congruence between research methods and theory, although some studies were not explicit in their theoretical framework.

\section{DISCUSSION}

The goal of this article is to address the theoretical, methodological, and definitional debates in the SoTL literature by discussing theory and methodology together, and to illustrate the tacit link between them using a framework and example studies. We briefly describe a broad range of learning theories and methodologies as well as the kinds of knowledge with which each methodology aligns. To address questions in the field about generalizability in SoTL, we have described many well-established qualitative research methodologies that make no claim to achieving generalizability in their findings. We implore SoTL researchers to move beyond the generalizability debate and broaden the range of perspectives they draw from in their research methodologies.

We have also shown that the predominant definition of SoTL as an inquiry "measuring systematic changes to teaching and improvements in learning" (Gurung \& Wilson, 2013) is only one kind of approach to SoTL which lies at the empirical end of the methodology spectrum. While we are in agreement with Felten's (2013) broad and inclusive definition of SoTL, we offer this framework to help flesh out his principle of being "methodologically sound" and to increase awareness and acceptance of the range of research methodologies which are used in a diverse range of disciplines, including education, and which may be used to contribute to our knowledge about teaching and learning. We suggest that general SoTL discourse needs to become more aware and accepting of this diversity because, in the words of Chick (2013), "if disciplinary perspectives are how scholars do their daily work, make meaning, think about the world, and interpret their experiences and those of others, they can't simply deny them or change them, nor would they want to" (p.19).

The example studies provide evidence that SoTL does, in fact, reach across multiple methodologies and theoretical perspectives. The examples not only illustrate our proposed framework but also demonstrate the limitations of the "mutt" metaphor, in that methodologies, theories, and the research question posed must be internally compatible. Our framework is not intended to be prescriptive or comprehensive, but to show the range of theory and methodology being used in SoTL work and to demonstrate that there is a relation between theory and methodology. We encourage researchers to not choose one 
without considering the other. In our experience, studies that have a methodology incompatible with a theoretical framework do not tend to be successful as one undermines the other. The result may be work that is not completed or published.

Finally, we hope that a broader knowledge of learning theory might also be useful to qualitative researchers in SoTL in order to help make sense of unanticipated findings. One of the strengths of qualitative research is that its open, emergent approach allows for the identification of new phenomena that may not have been anticipated. Hence, in contrast to quantitative studies where theory is identified early and informs the research design, in qualitative research theory may be used much later as a lens through which to interpret findings. For example, a qualitative or mixed methods study might start out with the intent to better understand students' stages of cognitive development related to a particular disciplinary concept, but end up uncovering an unanticipated finding related to gender or motivation. For this reason, as SoTL continues to embrace more qualitative research approaches (as do other fields), we expect that it will become more important for practitioners to be aware of different theoretical frameworks within which to place their findings.

In summary, we hope that this framework might engender better communication, understanding, and appreciation among disciplines and research traditions across the SoTL landscape. It may serve as a resource for practitioners steeped in one research tradition to understand the broader SoTL landscape, to find a point of entry into SoTL, and to communicate about SoTL with both their disciplinary and non-disciplinary colleagues. Finally, we suggest that this framework could serve as a starting point to map changes in the field over time.

\section{CONCLUSIONS}

This article has broadly outlined existing categories of learning theories and research methodologies and has used them to outline an inclusive framework to conceptualize SoTL. We suggest that in expanding understanding of underlying theories and methodological ranges, we can increase awareness of the kinds of questions that can be pursued in SoTL, and thus also address the debate about "what is SoTL." With this awareness, SoTL researchers might begin to wrestle with and address Kreber's (2013) criticism that "the discourse of evidence-based practice does not leave room for questions about the purposes and goals of our educational endeavours," arguing that "our understanding of evidence could be broadened so as to intentionally encourage a wider range of questions for enquiry" (p. 858).

The purpose of this paper is not to provide everything one needs to know about teaching and learning research methodologies and theoretical frameworks of learning. Methodologies and exemplars that have been highlighted here only scratch the surface of possibilities for further development of SoTL. Rather, it is our hope that we can advance the discussion of scholarship of teaching and learning past definitional and epistemological debates by describing the current context and practice of this emerging field, and by placing it within existing frameworks for research on teaching and learning. Finally, it is our hope that this article addresses McKinney's (2013) call for

more resources that offer examples, applications and discussions of critical issues of SoTL in disciplines beyond our own and in interdisciplinary SoTL 
efforts. Such resources help broaden our horizons and encourage cross-

disciplinary collaborations by sharing conceptual frameworks, methodologies, key results and practical applications that may be useful in our own classrooms and SoTL research (p. 3).

\section{ACKNOWLEDGEMENTS}

We wish to thank members of our SoTL community of practice, Miriam Carey, Sally Haney, Margy MacMillan, April McGrath, and Melanie Rathburn, where our discussions about methodology, theory, and orienting scholars to the field first germinated, and Mount Royal University's Institute for Scholarship of Teaching and Learning for supporting this work.

Janice Miller-Young is an Associate Professor and the Director of the Institute for Scholarship of Teaching and Learning at Mount Royal University.

Michelle Yeo is a faculty developer and Associate Professor in Mount Royal University's Academic Development Centre.

\section{REFERENCES}

Ambrose, S. A., Bridges, M.W., DiPietro, M., Lovett, M. C., \& Norman, M.K. (2010). How learning works: Seven research-based principles for smart teaching. Hoboken, NJ: Wiley.

Barrow, R. (2006). Empirical research into teaching. Interchange, 37(4), 287-397.

Bloom, B.S. (1956). Taxonomy of educational objectives: The classification of educational goals. Handbook I: Cognitive domain. New York, NY: David McKay Company.

Bernstein, D. (2010). Finding your place in the scholarship of teaching and learning. International Journal for the Scholarship of Teaching and Learning, 4(2).

Burton, L. (2002). Methodology and methods in mathematics education research: Where is "The Why?" In S. Goodchild \& L. English (Eds.), Researching mathematics classrooms: A critical examination of methodology (pp. 1-10). Westport, CT: Praeger.

Carey, M. (2012). In the valley of the giants: Cultivating intentionality and integration. International Journal for the Scholarship of Teaching and Learning, 6(1).

Chick, N. (2013) Difference, power and privilege in the scholarship of teaching and learning. In K. McKinney (Ed.), The scholarship of teaching and learning in and across the disciplines (pp. 15-33). Bloomington, IN: Indiana University Press.

Chick, N. (2014). 'Methodologically sound' under the 'big tent': An ongoing conversation. International Journal for the Scholarship of Teaching and Learning, 8(2).

Chism, N., Douglas, E., \& Hilson, W.J. (2010). Qualitative research basics: A guide for engineering educators. http://crlte.engin.umich.edu/wp-content/uploads/sites/7/2013/06 /Chism-Douglas-Hilson-Qualitative-Research-Basics-A-Guide-for-Engineering-Educators .pdf

Denzin, N.K., \& Lincoln, Y.S. (Eds.) (2013). Collecting and interpreting qualitative materials (4 ${ }^{\text {th }}$ ed.). Thousand Oaks, CA: Sage.

Dickson, K.L., \& Treml, M.M. (2013). Using assessment and SoTL to enhance student learning. New Directions for Teaching and Learning, 2013(136), 7-16. 
Easton, L., \& Hewson, K. (2010). Reflections on the interplay of race, whiteness and Canadian identity in a film studies classroom. Reception: texts, readers, audiences, history, 2, 116-148.

Ellsworth, E. (1997). Teaching positions: Difference, pedagogy and the power of address. New York, NY: Teachers College Press.

Felten, P. (2013). Principles of good practice in SoTL. Teaching \& Learning Inquiry: The ISSOTL Journal, 1(1), 121-125.

Daniels, L. (Producer) \& Forster, M. (Director). (2001). Monster's Ball. United States: Lee Daniels Entertainment.

Glassick, C.E., Huber, M.T., \& Maeroff, G.I. (1997). Scholarship assessed: Evaluation of the professoriate. San Francisco, CA: Jossey Bass Inc.

Grauerholz, L., \& Main, E. (2013). Fallacies of SoTL: Rethinking how we conduct our research, In K. McKinney (Ed.), The scholarship of teaching and learning in and across the disciplines (pp. 152-168). Bloomington, IN: Indiana University Press.

Gurung, A.R., \& Wilson, J.H. (2013). Doing the scholarship of teaching and learning: Measuring systematic changes to teaching and improvements in learning. New Directions in Teaching and Learning, 2013(136).

Gurung, A.R., \& Schwartz, B.M. (2013). Contributions from psychology: Heuristics for interdisciplinary advancement of SoTL. In K. McKinney (Ed.), The scholarship of teaching and learning in and across the disciplines (pp. 34- 53). Bloomington, IN: Indiana University Press.

Helberg, N., Heyes, C., \& Rohel, J. (2009). Thinking through the body: Yoga, philosophy, and physical education. Teaching Philosophy, 32(3), 263-284.

Hubball, H., \& Clarke, A. (2010). Diverse methodological approaches and considerations for SoTL in higher education. The Canadian Journal for the Scholarship of Teaching and Learning, 1(1).

Hutchings, P. (2000). Approaching the scholarship of teaching and learning. In P. Hutchings (Ed.), Opening lines: Approaches to the scholarship of teaching and learning (pp. 1-10). Menlo Park, CA: Carnegie Foundation for the Advancement of Teaching.

Kanuka, H. (2011). Keeping the scholarship in the scholarship of teaching and learning. International Journal for the Scholarship of Teaching and Learning, 5(1).

Kilk, J. \& Lee, S. (Producers); \& Lee, S. (Director). (2000) Bamboozled [Motion Picture]. United States: 40 Acres and a Mule Filmworks.

Kreber, C. (2013). Empowering the scholarship of teaching: An Arendtian and critical perspective. Studies in Higher Education, 38(6), 857-869.

Lave, J., \& Wenger, E. (1991). Situated learning: Legitimate peripheral articipation. Cambridge, England: Cambridge University Press.

Leamson, R. (1999). Thinking about teaching and learning: Developing habits of learning with first year college and university students. Sterling, VA: Stylus.

Leder, D. (1990). The Absent body. Chicgo: University of Chicago Press.

Lincoln, Y.S., \& Guba, E.G. (1985). Naturalistic inquiry. Beverly Hills, CA: Sage.

MacMillan, M. (2014). Student connections with academic texts: A phenomenographic study of reading. Teaching in Higher Education, 19(8), 943-954. 
Manarin, K. (2012). Reading value: Student choice in reading strategies. Pedagogy, 12(2), 281-297.

Maslow, A. (1970). Motivation and personality ( $2^{\text {nd }}$ Ed.). Upper Saddle River, NJ: Pearson Education, Inc.

McGrath, A. (2014). Just checking in: The effect of an office hour meeting and learning reflection in an introductory statistics course. Teaching of Psychology, 41(1), 83-87.

McKinney, K. (2013). Introduction to SoTL in and across the disciplines. In K. McKinney (Ed.), The scholarship of teaching and learning in and across the disciplines (pp. 1-11). Bloomington, IN: Indiana University Press.

Middendorf, J., \& Pace, D. (2004). Decoding the disciplines: A model for helping students learn disciplinary ways of thinking. New Directions in Teaching and Learning, 98, pp. 1-12.

Miller-Young, J.E. (2013). Calculations and expectations: How engineering students describe three-dimensional forces. The Canadian Journal for the Scholarship of Teaching and Learning, 4(1).

Naested, I., Potvin, B., \& Waldron, P. (2004). Understanding the landscape of teaching. Toronto, Canada: Pearson Prentice Hall.

Nelson, C. (2003). Doing it: Examples of several of the different genres of the scholarship of teaching and learning. Journal on Excellence in College Teaching, 14(2).

Poole, G. (2013a). Controversies, debates, and tensions in SoTL. Retrieved from http://www issotl13.com

Poole, G. (2013b). Square one: What is research? In K. McKinney (Ed.), The scholarship of teaching and learning in and across the disciplines (pp. 135-151). Bloomington, IN: Indiana University Press.

Seitz, D. (2004). Who can afford critical consciousness?: Practicing a pedagogy of humility. Creskill, NJ: Hampton Press.

Streveler, R.A., Litzinger, T.A., Miller, R.L., \& Steif, P.S. (2008). Learning conceptual knowledge in the engineering sciences: Overview and future research directions. Journal of Engineering Education, 97(3), 279-294.

Zull, J.E. (2002). The art of changing the brain: Enriching the practice of teaching by exploring the biology of learning. Sterling, VA: Stylus. 